\title{
Modulated Backscatter for Ultra-Low Power Uplinks from Wearable and Implantable Devices
}

\author{
Stewart J. Thomas \\ stewart.t@gmail.com \\ Jordan S. Besnoff
jordan.besnoff@duke.edu \\ Matthew S. Reynolds \\ matt.reynolds@duke.edu \\ Department of Electrical and Computer Engineering \\ Duke University \\ Durham, NC 27708
}

\begin{abstract}
Wearable and implantable wireless biomedical devices are often constrained by the limited bandwidth and high power consumption of their communication links. The VHF or UHF transceivers (e.g. MICS radios) traditionally used for this communication function have relatively high power consumption, on the order of $\mathrm{mW}$, due to the high bias currents required for the analog sections of the radio. To reduce overall power consumption, both the data rate and the duty cycle of the radio are usually minimized, because the lifetime of the device is limited by the energy density of available battery technologies.

Recent innovations in modulated backscatter techniques offer the possibility of a radical reduction in the power cost and complexity of the data uplink, while significantly improving data rate. This is achieved by a re-partitioning of the communication link. Backscatter techniques shift the burden of power cost and complexity from the remote device to a base station. Instead of actively transmitting an $\mathrm{RF}$ signal, the remote device uplinks data to the base station by modulating its reflected field.

We present two ultra-low power biotelemetry systems that leverage modulated backscatter in both the near-field and far-field propagation regimes. The first example operates in the far field and is designed to telemeter multiple channels of neural/EMG signals from dragonflies in flight. This device has a mass of $38 \mathrm{mg}$, a data rate of $5 \mathrm{Mbit} / \mathrm{s}$, and a range of approximately $5 \mathrm{~m}$. The second example operates in the near field and is designed to be implanted in mice. The sensor has a maximum implant depth of $6 \mathrm{~cm}$ and can transmit at data rates of up to $30 \mathrm{Mbit} / \mathrm{s}$. The power cost of the animal side of both data links is $4.9 \mathrm{pJ} / \mathrm{bit}$ and $16.4 \mathrm{pJ} / \mathrm{bit}$ respectively.
\end{abstract}

\section{Categories and Subject Descriptors}

B.4.4 [Input/Output and Data Communications]: Performance Analysis and Design Aids-Simulation, Verifica-

Permission to make digital or hard copies of all or part of this work for personal or classroom use is granted without fee provided that copies are not made or distributed for profit or commercial advantage and that copies bear this notice and the full citation on the first page. To copy otherwise, to republish, to post on servers or to redistribute to lists, requires prior specific permission and/or a fee.

MedCOMM'12, August 13, 2012, Helsinki, Finland.

Copyright 2012 ACM 978-1-4503-1478-7/12/08/12/08 ...\$15.00. tion; B.4.1 [Input/Output and Data Communications]:

Data Communications Devices-receivers, transmitters

\section{General Terms}

Design, Experimentation

\section{Keywords}

backscatter, biotelemetry, low-power communication

\section{INTRODUCTION}

Wearable and implantable biomedical devices are often severely power limited due to the limited energy density of available battery technologies. Wireless communication usually accounts for a substantial portion of the power budget of these devices, due to the high currents required by onchip very-high or ultra-high frequency (VHF / UHF) oscillators and frequency synthesizers for Medical Implant Communication Service (MICS), Bluetooth, 802.11, and most other wireless standards. To reduce overall power consumption, both the amount of data transferred and the duty cycle of the radio are carefully minimized, leading to many published schemes for minimizing radio duty cycle in power constrained operation.

Because the communication subsystem can account for a significant fraction of total system power [14], research in the area of low-power sensor networks and devices often assumes that power cost to transmit data is significantly greater than on-chip processing or data storage [9]. This power tradeoff between on-chip processing and data uplink has been further analyzed in detail [8].

In this paper we consider an alternative communication method using modulated backscatter, which offers the possibility of continuous, high data rate telemetry uplink at attractively low power consumption at the wearable / implantable device. This is achieved by a re-partitioning of the data link in terms of both circuit complexity and power allocation. Circuit complexity is shifted from the wearable / implantable device to a base station which is responsible for generation and transmission of the RF carrier used for communication. The wearable / implantable device does not generate its own RF carrier, so its on-chip RF oscillator or frequency synthesizer can be eliminated. Instead, the remote device transmits data to the base station by modulating its reflected power. This can be realized simply with a single transistor in parallel with an antenna, switching at baseband frequencies. Modulated backscatter thus allows 
Forward Link

(Power + Data Carrier)

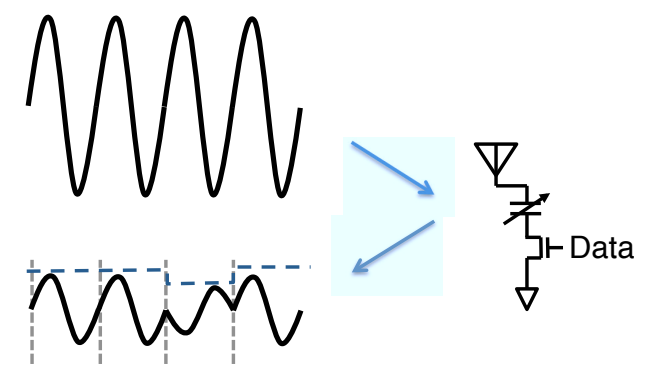

Return Link (Modulated Data)

Figure 1: Conceptual schematic of a backscatter data uplink. The backscatter modulator can be as simple as a single FET switched by a baseband digital data signal.

data to be uplinked over a high-frequency carrier with no on-chip transistors biased for UHF operation.

Single-chip backscatter modulators were originally developed for passive UHF RFID tags employing binary ASK or PSK at relatively low data rates up to $640 \mathrm{kbps}$ [10]. However, recent work by the authors has shown that modulated backscatter can be extended to include modulation schemes of arbitrary complexity, such as $M$-ary quadrature amplitude modulation (QAM) $[17,21]$. This technique has been used to wirelessly telemeter data over a backscatter link with a data rate of $96 \mathrm{Mbit} / \mathrm{s}$ with an energy consumption of only $15.5 \mathrm{pJ} /$ bit [20]. This is comparable to 802.11 (WiFi) in terms of data rate, but at power levels over $100 \mathrm{X}$ lower than previously reported WiFi systems.

In this paper, we summarize two ultra-low power wireless biotelemetry systems currently being developed. These systems employ modulated backscatter in both the far field $(d>>\lambda)$ and the near field $(d<<\lambda)$ RF propagation regimes.

The first example operates in the far field propagation regime $(d \approx 5 \mathrm{~m}, \lambda \approx 33 \mathrm{~cm})$ and is designed to telemeter up to 10 neural and 4 EMG channels from dragonflies during flight. This device has a total packaged mass of $38 \mathrm{mg}$, a data rate of $5 \mathrm{Mbit} / \mathrm{s}$, and a range of approximately $5 \mathrm{~m}$ $[18,19]$. The far field device is fully passive and derives all operating power from the incident RF signal from the base station. This further reduces the size and mass of the device by eliminating all batteries from the wireless device.

The second example is a near field communication link $(d \leq 6 \mathrm{~cm}, \lambda \approx 33 \mathrm{~cm})$ designed for implantation in small animals such as mice. This device has a maximum implant depth of $6 \mathrm{~cm}$ and can transmit at data rates up to $30 \mathrm{Mbit} / \mathrm{s}$.

The energy cost per bit on the animal side of both of these backscatter data uplinks is $4.9 \mathrm{pJ} / \mathrm{bit}$ and $16.4 \mathrm{pJ} / \mathrm{bit}$ respectively. This is a significant reduction compared to existing "ultra-low power" biomedical telemetry solutions with power costs of over $60 \mathrm{~nJ} /$ bit when transmitting at a maximum data rate of $50 \mathrm{kbps}$ [11].

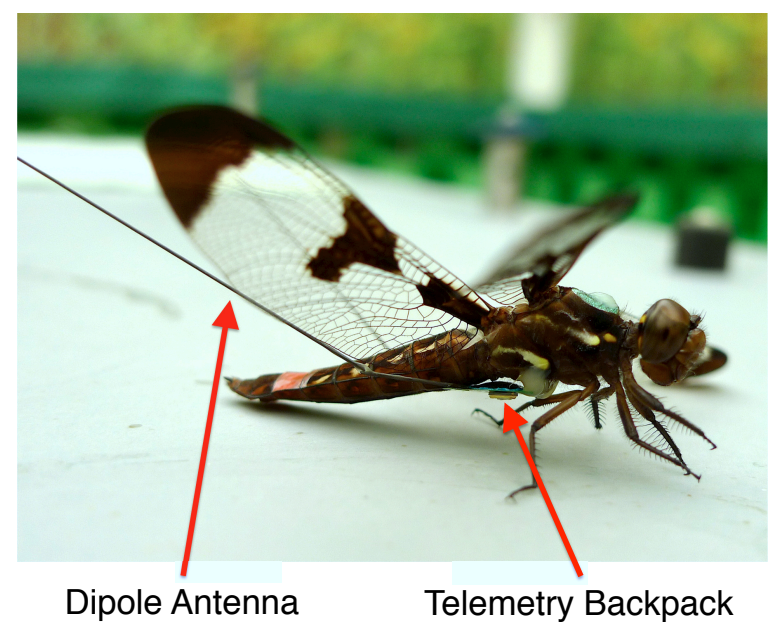

Figure 2: Photograph of biosignal acquisition backpack attached to a dragonfly.

\section{FAR FIELD MODULATED BACKSCAT- TER FOR WEARABLE DEVICES}

Recent work in the author's laboratory has resulted in a digital neural/EMG telemetry system that is small and lightweight enough to permit recording from insects during flight $[18,19]$. A photograph of the telemetry backpack attached to a dragonfly, Libellula lydia, is shown in Fig. 2. This species of dragonfly weighs about $400 \mathrm{mg}$ and can carry payloads up to $33 \%$ of its body weight (about $130 \mathrm{mg}$ ) without interfering with normal foraging behavior. This small payload capacity imposes significant engineering challenges in designing instrumentation capable of wirelessly recording in-flight neural activity.

A system block diagram is shown in Fig. 3. The base station transmits a $4 \mathrm{~W}, 915 \mathrm{MHz}$ signal from a perch-mounted patch antenna to an $8 \mathrm{~cm}$ dipole antenna attached to the telemetry IC. The telemetry IC employs RF power harvesting to supply DC its operating power, so it is battery-free. The total flight package mass is only $38 \mathrm{mg}$. The chip is designed for operation in the $902-928 \mathrm{MHz}$ ISM band and communicates 16 channels (10 neural, 4 EMG, 2 general purpose DC) of sampled full-waveform data at a total data rate of $5 \mathrm{Mbit} / \mathrm{s}$. The chip has a theoretical maximum operating range of approximately $5 \mathrm{~m}$ when using a $4 \mathrm{~W}(+36 \mathrm{dBm})$ transmitter.

Table 1 compares this system with other biotelemetry systems designed for operation with small, freely-moving animals. With the exception of [22], which is also RF-powered, existing systems weigh too much to permit natural flight behavior from a dragonfly, largely due to the weight of bulk energy storage. Such small batteries or supercapacitors also have the significant disadvantage of short useful lifetimes, often less than 1 hour. In contrast, the backscatter-based device has unlimited lifetime due to its battery-free operation. In this system, modulation for the data uplink is realized using a single modulating FET and a weighted capacitor array resulting in a digitally configurable impedance that controls the modulation angle of the BPSK backscatter. By avoiding the use of an on-chip UHF oscillator or frequency synthesizer, no transistors are biased for UHF operation and a significant reduction in operating power is achieved. At a 
Table 1: Comparison of Selected Low-Power Far-Field Wireless Biotelemetry Systems

\begin{tabular}{|c|c|c|c|c|c|c|}
\hline & $\begin{array}{c}\text { Ando } \\
{[1]}\end{array}$ & $\begin{array}{c}\text { Takeuchi } \\
{[16]}\end{array}$ & $\begin{array}{l}\text { Mohseni } \\
{[12]}\end{array}$ & $\begin{array}{c}\text { Yeager } \\
{[22]}\end{array}$ & $\begin{array}{c}\text { Harrison } \\
{[4]}\end{array}$ & $\begin{array}{l}\text { Thomas } \\
{[18,19]}\end{array}$ \\
\hline Year & 2002 & 2004 & 2005 & 2010 & 2011 & 2012 \\
\hline Power Consumption & $3.6 \mathrm{~mW}$ & $10 \mathrm{~mW}$ & $2.2 \mathrm{~mW}$ & $16.56 \mu \mathrm{W}$ & $1.0 \mathrm{~mW}$ & $1.23 \mathrm{~mW}$ \\
\hline Signals Transmitted & 2 EMG & 1 neural & 3 neural & 1 temperature & $\begin{array}{l}2 \text { neural } \\
2 \text { EMG }\end{array}$ & $\begin{array}{c}10 \text { neural } \\
4 \text { EMG } \\
2 \text { auxiliary inputs }\end{array}$ \\
\hline Signal Bandwidth & $200 \mathrm{~Hz}-2 \mathrm{kHz}$ & $20 \mathrm{~Hz}-10 \mathrm{kHz}$ & $50 \mathrm{~Hz}-9.1 \mathrm{kHz}$ & $50 \mathrm{~Hz}$ & $\begin{array}{c}5.2 \mathrm{kHz} \text { (neural) } \\
280 \mathrm{~Hz} \text { (EMG) }\end{array}$ & $\begin{array}{l}10 \mathrm{kHz} \text { (neural) } \\
700 \mathrm{~Hz}(\mathrm{EMG})\end{array}$ \\
\hline Operating Range & $5 \mathrm{~m}$ & $16 \mathrm{~m}$ & $0.5 \mathrm{~m}$ & $3 \mathrm{~m}^{\dagger}$ & $2 \mathrm{~m}$ & $5 \mathrm{~m}$ \\
\hline Battery Life & $0.5 \mathrm{~h}$ & $0.5 \mathrm{~h}$ & - & Battery-free & $5 \mathrm{~h}$ & Battery-free \\
\hline Total Mass & $250 \mathrm{mg}$ & $\begin{array}{c}100 \mathrm{mg} \\
\text { (w/out battery) }\end{array}$ & $1,100 \mathrm{mg}$ & $250 \mathrm{mg}$ & $170 \mathrm{mg}$ & $38 \mathrm{mg}$ \\
\hline Approximate Size & $7.5 \times 6.25 \mathrm{~mm}$ & $15 \times 8 \mathrm{~mm}$ & $17 \times 12 \mathrm{~mm}$ & $9.1 \times 7.3 \mathrm{~mm}$ & $6 \times 5 \mathrm{~mm}$ & $6.8 \times 4.6 \mathrm{~mm}$ \\
\hline Off Chip Components & - & 18 & 3 & 16 & 1 & 3 \\
\hline Supply Voltage & $1.55 \mathrm{~V}$ & $3.0 \mathrm{~V}$ & $3.0 \mathrm{~V}$ & $1.8 \mathrm{~V}$ & $1.5 \mathrm{~V}$ & $1.31 \mathrm{~V}$ \\
\hline Telemetry Frequency & $82-85 \mathrm{MHz}$ & $85 \mathrm{MHz}$ & $96 \mathrm{MHz}$ & $902-928 \mathrm{MHz}$ & $905 \mathrm{MHz}$ & $902-928 \mathrm{MHz}$ \\
\hline Telemetry Modulation & analog FM & analog FM & analog FM & digital backscatter & digital FSK & $\begin{array}{c}\text { digital BPSK } \\
\text { backscatter }\end{array}$ \\
\hline Target animal(s) & hawkmoth & cockroach & $\begin{array}{l}\text { marmoset } \\
\text { monkey }\end{array}$ & hawkmoth & $\begin{array}{l}\text { locust, elec. fish, } \\
\text { dragonfly }\end{array}$ & dragonfly \\
\hline
\end{tabular}

$\dagger$ Using commercial off-the-shelf (COTS) EPC Gen 2 UHF RFID reader

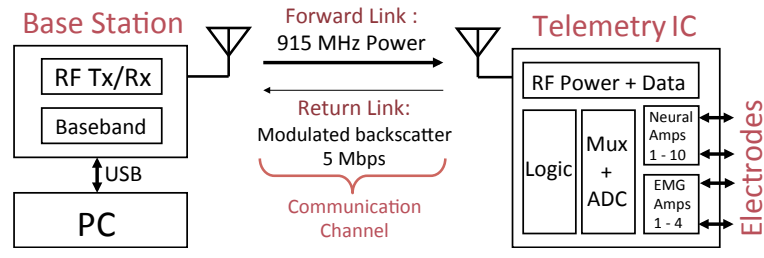

Figure 3: Block diagram of the far-field system.

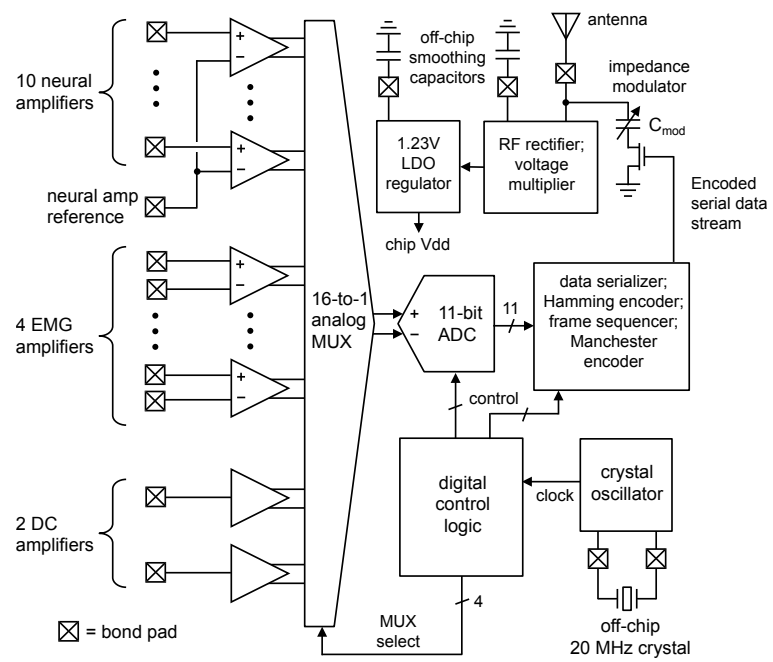

Figure 4: Simplified schematic of the telemetry IC.

data rate of $5.0 \mathrm{Mbps}$, the entire communication subsystem accounts for only $2 \%(24.6 \mu \mathrm{W})$ of the total DC system power consumption $(1.23 \mathrm{~mW})$, so continuous telemetry is achieved with minimal power penalty.

The dragonfly chip is capable of a $14 \mathrm{X}$ improvement in transmitted data rate when compared to similar devices which use an active radio [4]. The power breakdown, Fig. 5, shows the primary advantage of the backscatter communication modality - a majority of power is dedicated to the circuits used in signal acquisition, so power allocation can
Table 2: Telemetry IC power breakdown (measurement vs. simulation)

\begin{tabular}{lr}
\hline \hline Neural amplifiers & $160 \mu \mathrm{A}$ \\
EMG amplifiers & $1 \mu \mathrm{A}$ \\
DC amplifiers & $90 \mu \mathrm{A}$ \\
Analog mux & $139 \mu \mathrm{A}$ \\
Amplifier / mux bias generators & $80 \mu \mathrm{A}$ \\
11-bit ADC and digital control logic & $320 \mu \mathrm{A}$ \\
LDO voltage regulator & $60 \mu \mathrm{A}$ \\
Crystal oscillator & $70 \mu \mathrm{A}$ \\
Backscatter modulator & $15 \mu \mathrm{A}$ \\
\hline Simulated Total IC current & $935 \mu \mathrm{A}$ \\
Measured Total IC current & $940 \mu \mathrm{A}$ \\
& \\
Min. unregulated supply voltage & $1.31 \mathrm{~V}$ \\
Simulated Total IC power & $1.22 \mathrm{~mW}$ \\
Measured Total IC power & $1.23 \mathrm{~mW}$
\end{tabular}

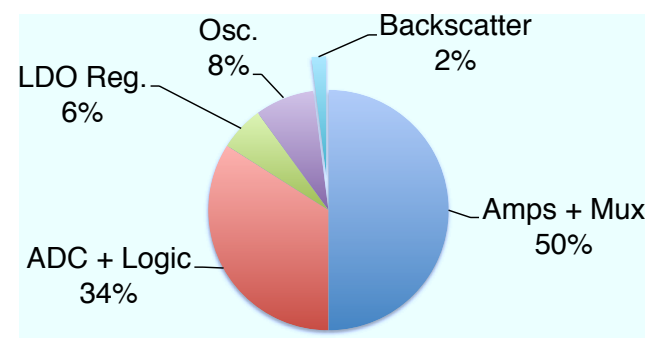

Figure 5: Power dissipation by subystem of the chip.

be focused on the essential task of obtaining high quality signals.

\section{NEAR FIELD MODULATED BACKSCAT- TER FOR IMPLANTED DEVICES}

For implantable devices, near field modulated backscatter is a promising approach to high bandwidth communication. In contrast to far field electromagnetic communication (where $d>>\lambda$ ) in which energy is propagated by a combination of electric and magnetic field components, evanescent modes dominate in the near field where $d<<\lambda$. Most 
Table 3: Performance of selected high data rate implantable communication links

\begin{tabular}{|c|c|c|c|c|c|c|}
\hline & \multicolumn{3}{|c|}{ Inductively Coupled Load Modulation } & \multicolumn{2}{|c|}{ On-Chip RF Oscillator } & \multirow{2}{*}{$\begin{array}{c}\text { Besnoff } \\
{[2]} \\
2012 \\
\end{array}$} \\
\hline & $\begin{array}{c}\text { Mollazadeh [13] } \\
2008\end{array}$ & $\begin{array}{c}\text { Mandal [7] } \\
2008\end{array}$ & $\begin{array}{l}\mathrm{Hu}[6] \\
2005\end{array}$ & $\begin{array}{c}\text { Harrison }[5] \\
2007\end{array}$ & $\begin{array}{c}\text { Harrison }[4] \\
2011\end{array}$ & \\
\hline Operating Frequency & $4 \mathrm{MHz}$ & $25 \mathrm{MHz}$ & $10 \mathrm{MHz}$ & $433 \mathrm{MHz}$ & $905 \mathrm{MHz}$ & $915 \mathrm{MHz}$ \\
\hline Radio Power & $1.8 \mathrm{~mW}(\mathrm{Rx})$ & $100 \mu \mathrm{W}(\mathrm{Tx})$ & $0.61 \mathrm{~mW}(\mathrm{Rx})$ & $1.81 \mathrm{~mW}$ & $0.27 \mathrm{~mW}$ & $0.493 \mathrm{~mW}$ \\
\hline Data Rate & $32 \mathrm{kbps}$ & $2.8-4.0 \mathrm{Mbps}$ & $1.12 \mathrm{Mbps}$ & $330 \mathrm{kbps}$ & $345.6 \mathrm{kbps}$ & $30 \mathrm{Mbps}$ \\
\hline Energy/bit & - & - & - & $5.48 \mathrm{~nJ} / \mathrm{bit}$ & $0.781 \mathrm{~nJ} / \mathrm{bit}$ & $16.4 \mathrm{pJ} / \mathrm{bit}$ \\
\hline
\end{tabular}

implantable devices, particularly in small animals, have an implant depth of less than $10 \mathrm{~cm}$. At UHF carrier frequencies $(902-928 \mathrm{MHz})$, the wavelength $\lambda \approx 33 \mathrm{~cm}$, so evanescent modes dominate. In the near field regime, signals can be coupled via the magnetic component of the evanescent mode. Because animal tissues have low magnetic permeability, the magnetic field is relatively unaffected by tissue proximity, and even at high carrier frequencies the losses in tissue are manageable.

The near field UHF modulated backscatter modality is distinct from near field inductive communication techniques at low carrier frequencies such as NFC. These systems, where $f<30 \mathrm{MHz}$, are sometimes called load modulation. Load modulation systems are based on transformer coupling between the reader's primary coil and the secondary coil in the implant. Thus, communication is not achieved through scattered fields but rather via a switched load at the transponder antenna inducing a voltage change at the external system [3]. Given the low carrier frequencies of inductive load modulation systems, bandwidth is severely limited as shown in Table 3.

To gain insight into the behavior of backscatter based implants at UHF frequencies, the two-way backscatter channel has been modeled using a proxy system shown in Figure 6 prior to any testing on a live animal. The proxy system consists of a polyethylene tank containing 6 liters of $0.91 \%$ mass / volume saline. The path loss between the segmented loop antenna and the small loop transponder antenna has been characterized using a network analyzer both in the saline tank and in free space. Not surprisingly, the small loop transponder experiences higher path loss in saline than free space, as saline has a much higher relative permittivity $\left(\epsilon_{r} \approx 80\right)$ than air, and a larger loss tangent at the tested frequencies, and is thus a higher loss dielectric fluid [15].

A prototype implantable backscatter modulator, powered by a CR2032 coin cell, was fabricated as shown in Figure 7. It uses a $10 \mathrm{~mm}$ diameter magnetic loop antenna that is connected to a low-power backscatter modulator that can be set to a rate of $7.5 \mathrm{Mbps}, 15 \mathrm{Mbps}$, or $30 \mathrm{Mbps}$. In an actual implant, the circuitry can be reduced to a single chip on a thin substrate, while the bulky connectors shown would not be required. The external base station transceiver for this near field system consists of a specialized segmented loop near field antenna, which creates an approximately uniform magnetic field in close proximity to lossy, conductive dielectrics such as the saline proxy or actual biological tissue. The measured backscatter signal strength at $30 \mathrm{Mbps}$ is shown in Figure 8.

Near field UHF backscatter naturally lends itself to low power implementation, as shown in Table 4 . The main communication element is a CMOS RF switch that connects one of two load impedances to the loop antenna. The power con-

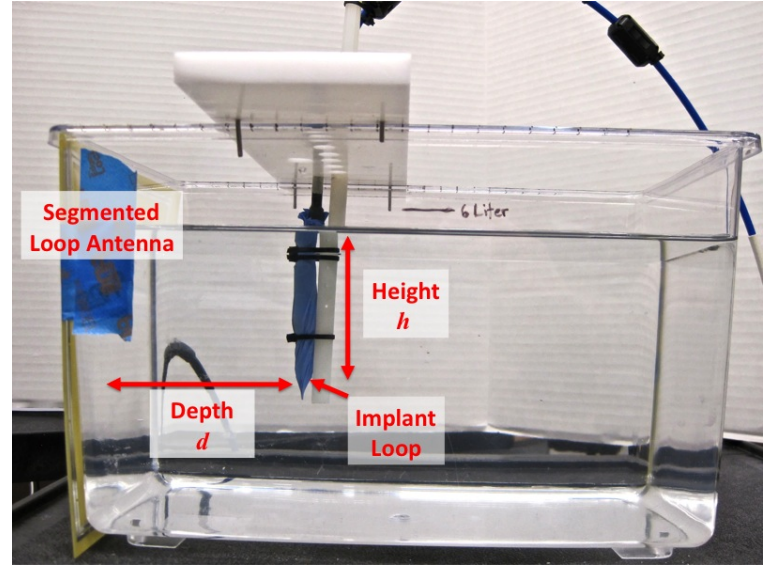

Figure 6: Saline tank proxy system used for UHF near field tests.

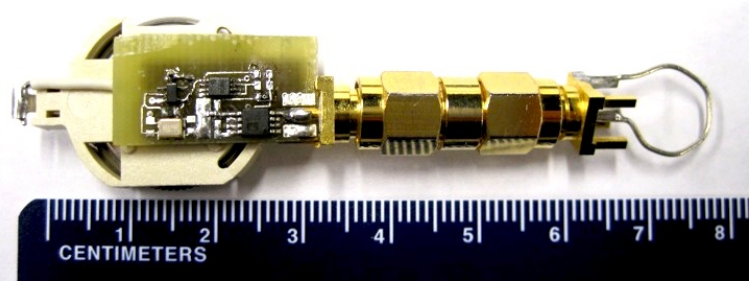

Figure 7: Near field modulated backscatter test circuit.

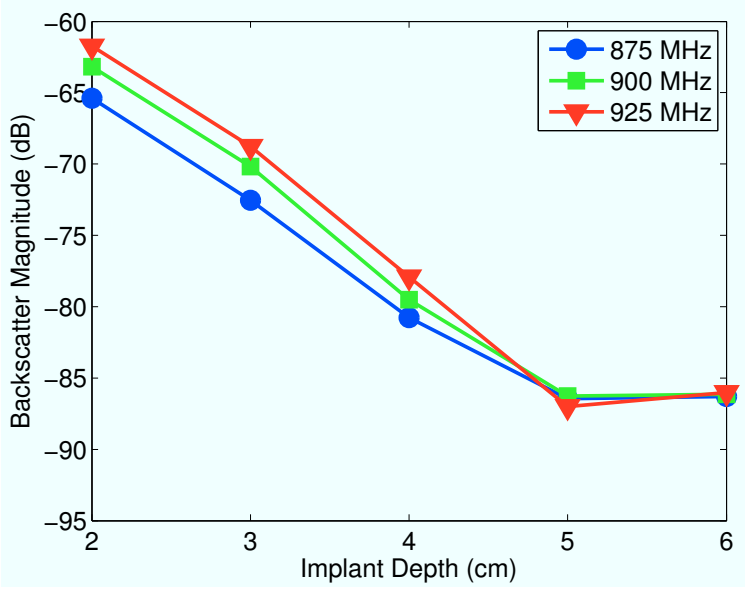

Figure 8: Measured $30 \mathrm{MHz}$ backscatter return power referenced to base station carrier power. 
Table 4: Power consumption and energy performance

\begin{tabular}{|c|c|c|c|c|}
\hline Backscatter Frequency & Supply Voltage $(\mathrm{V})$ & Current $(\mu \mathrm{A})$ & Power $(\mathrm{mW})$ & Energy/bit $(\mathrm{pJ} / \mathrm{bit})$ \\
\hline $7.5 \mathrm{MHz}$ & 3.01 & 67.8 & 0.204 & 27.2 \\
\hline $15 \mathrm{MHz}$ & 3.01 & 135 & 0.406 & 27.0 \\
\hline $30 \mathrm{MHz}$ & 3.01 & 164 & 0.493 & 16.4 \\
\hline
\end{tabular}

sumed by the switch increases with backscatter rate, while the energy per backscattered bit is as low as $16.4 \mathrm{pJ} / \mathrm{bit}$.

Near field UHF modulated backscatter provides for a lowpower, high data rate uplink from implantable biomedical devices. This technology is especially applicable to multielectrode telemetry devices for acquiring data from multiple neurons, where the capability of transmitting large amounts of raw digitized data without compression to an external base station is essential. This transfers the burden of computation from the implant to the external system, allowing for reduction of power dissipation on the implant which is in contact with highly temperature sensitive neural tissue. The proposed system provides penetration depths up to $6 \mathrm{~cm}$ in a medium that is expected to be more lossy than actual biological tissue, with communication rates up to $30 \mathrm{Mbps}$. The proposed system is competitive in terms of power consumption with those in Table 3, while far outperforming competitive systems in maximum data rate and energy per bit.

\section{CONCLUSIONS}

Because of their origins in low data rate UHF RFID tags, backscatter communication links have traditionally been considered as a low-bandwidth communication channel. However, the two example systems in this paper show that highbandwidth communication using modulated backscatter is both practical and very attractive from a power efficiency (energy per transmitted bit) perspective. By eliminating almost all on-chip RF circuitry, the backscatter uplink offers significant savings in power cost and implantable/wearable device complexity. These benefits are also disruptive to the existing paradigm for low-power communication links, where it is often assumed that wireless data transmission has a higher power cost than on-chip computation. Future devices that employ modulated backscatter will offer higher uplink data rates, at much lower power cost, than similar devices using traditional wireless communication. We have also shown that high-bandwidth modulated backscatter can be applied to both implantable and wearable devices, given the near field and far field RF propagation domains.

\section{Acknowledgments}

This material is based in part upon work supported by the National Science Foundation under Grant Numbers CBET0931924 and CMMI-0800858. Additional support has been provided by the Howard Hughes Medical Institute.

\section{REFERENCES}

[1] N. Ando, I. Shimoyama, and R. Kanzaki. A dual-channel FM transmitter for acquisition of flight muscle activities from the freely flying hawkmoth, agrius convolvuli. Journal of Neuroscience Methods, 115(2):181 - 187, 2002.
[2] J. S. Besnoff and M. S. Reynolds. Near field modulated backscatter for in vivo biotelemetry. In 2012 IEEE International Conference on RFID, pages 135-140, April 2012.

[3] K. Finkenzeller. RFID Handbook. Wiley, 2nd edition, 2003. Chapter 3, pages 42-43.

[4] R. R. Harrison, H. Fotowat, R. Chan, R. J. Kier, R. Olberg, A. Leonardo, and F. Gabbiani. Wireless neural/emg telemetry systems for small freely moving animals. IEEE Transactions on Biomedical Circuits and Systems, 5(2):103 - 111, April 2011.

[5] R. R. Harrison, P. T. Watkins, R. J. Kier, R. O. Lovejoy, D. J. Black, B. Greger, and F. Solzbacher. A low-power integrated circuit for a wireless 100-electrode neural recording system. IEEE Journal of Solid-State Circuits, 42(1):123-133, January 2007.

[6] Y. Hu and M. Sawan. A fully integrated low-power BPSK demodulator for implantable medical devices. IEEE Transactions on Circuits and Systems -I: Regular Papers, 52(12):2552-2562, December 2005.

[7] S. Mandal and R. Sarpeshkar. Power-efficient impedance-modulation wireless data links for biomedical implants. IEEE Transactions on Biomedical Circuits and Systems, 2(4):301-315, December 2008.

[8] W. Marnane, S. Faul, C. Bleakley, R. Conway, E. Jones, E. Popovici, M. de la Guia Solaz, F. Morgan, and K. Patel. Energy efficient on-sensor processing in body sensor networks. In IEEE Engineering in Medicine and Biology Society, EMBC 2010, pages 2025 - 2029, Sept. 2010.

[9] G. Mathur, P. Desnoyers, P. Chukiu, D. Ganesan, and P. Shenoy. Ultra-low power data storage for sensor networks. ACM Transactions on Sensor Networks, 5(4):33:1-33:34, Nov. 2009.

[10] EPC Global US. Class 1 Generation 2 UHF RFID protocol for operation at $860 \mathrm{MHz}-960 \mathrm{MHz}$, version 1.0.9. Available online, http://www.epcglobalus.org/, 2005.

[11] Toumaz Microsystems Ltd. Telran tz1053: Toumaz extremely low power radio network. Electronic, February 2012.

[12] P. Mohseni, K. Najafi, S. Eliades, and X. Wang. Wireless multichannel biopotential recording using an integrated FM telemetry circuit. IEEE Transactions on Neural Systems and Rehabilitation Engineering, 13(3):263 - 271, September 2005.

[13] M. Mollazadeh, K. Murari, H. Schwerdt, X. Wang, N. Thakor, and G. Cauwenberghs. Wireless multichannel acquisition of neuropotentials. In IEEE Biomedical Circuits and Systems Conference, 2008, pages 49-52, Baltimore, MD, November 2008.

[14] V. Pop, R. de Francisco, H. Pflug, J. Santana, H. Visser, R. Vullers, H. de Groot, and B. Gyselinckx. 
Human++: wireless autonomous sensor technology for body area networks. In Proceedings of the 16th Asia and South Pacific Design Automation Conference, ASPDAC 2011, pages 561-566, Piscataway, NJ, USA, 2011. IEEE Press.

[15] A. Stogryn. Equations for calculating the dielectric constant of saline water. IEEE Transactions on Microwave Theory and Techniques, 19(8):733-736, 1971.

[16] S. Takeuchi and I. Shimoyama. A radio-telemetry system with a shape memory alloy microelectrode for neural recording of freely moving insects. IEEE Transactions on Biomedical Engineering, 51(1):133137, January 2004.

[17] S. Thomas and M. Reynolds. QAM backscatter for passive UHF RFID tags. In 2010 IEEE International Conference on RFID, pages 210 - 214, April 2010.

[18] S. J. Thomas, R. R. Harrison, A. Leonardo, and M. S. Reynolds. A battery-free multi-channel digital neural/EMG telemetry system for flying insects. In IEEE Biomedical Circuits and Systems Conference, pages $229-232,2011$.
[19] S. J. Thomas, R. R. Harrison, A. Leonardo, and M. S. Reynolds. A battery-free multi-channel digital neural/EMG telemetry system for flying insects. IEEE Transactions on Biomedical Circuits and Systems, page (Submitted), 2012.

[20] S. J. Thomas and M. S. Reynolds. A 96 Mbit/sec, 15.5 pJ/bit 16-QAM modulator for UHF backscatter communication. In 2012 IEEE International Conference on RFID, pages 185-190, April 2012.

[21] S. J. Thomas, E. Wheeler, J. Teizer, and M. S. Reynolds. Quadrature amplitude modulated backscatter in passive and semipassive UHF RFID systems. IEEE Transactions on Microwave Theory and Techniques, 60(4):1175-1182, 2012.

[22] D. Yeager, F. Zhang, A. Zarrasvand, N. George, R. Daniel, and B. Otis. A $9 \mu \mathrm{A}$, addressable Gen2 sensor tag for biosignal acquisition. IEEE Journal of Solid-State Circuits, 45(10):2198-2209, Oct. 2010. 